\title{
AUTONOMÍA UNIVERSITARIA HOY: UNA REFLEXIÓN NECESARIA
}

\section{UNIVERSITY AUTONOMY TODAY: A REFLECTION NEEDED}

\author{
Luis Muñoz Varela*
}

\author{
RESUMEN
}

El presente artículo tiene por finalidad hacer una breve reflexión en torno al concepto de la autonomía universitaria, tomando como marco de referencia el significado que ese concepto ha tenido en la universidad latinoamericana, a partir de la Reforma Universitaria de 1918, así como, la acepción que se le dio en Costa Rica con motivo de la creación de la Universidad de Costa Rica, en 1940. Se abordan algunas de las principales cuestiones que en el presente han venido a tener una repercusión significativa para la universidad pública y por consiguiente, para la autonomía universitaria.

PALABRAS CLAVE: UNIVERSIDADES * ENSEÑANZA PÚBLICA * AUTONOMÍA * REFORMA DE LA EDUCACIÓN * MOVIMIENTO DE CÓRDOBA

\section{ABSTRACT}

This article has the main object to reflect briefly about the concept of university autonomy, taking as reference frame the meaning that this concept has had on Latin American universities, since University Reform in 1918, as much as the connotation that was given to Costa Rica in relation of the creation of the University of Costa Rica, in 1940. It addresses some of the main issues that in the present have come to have a significant impact to the public university and therefore, for the university autonomy.

KEYWORDS: UNIVERSITIES * PUBLIC EDUCATION * AUTONOMY * EDUCATIONAL REFORM * CORDOBA MOVEMENT

Instituto de Investigaciones en Educación (INIE) de la Universidad de Costa Rica (UCR).

luis.munoz@ucr.ac.cr 


\section{PRESENTACIÓN}

En 2010, en la Universidad de Costa Rica (ucR), el Consejo Universitario acordó declarar la fecha del 12 de abril como Día de la Autonomía Universitaria. Ese acuerdo se tomó a raíz de la situación ocurrida el 12 de abril de 2010, cuando agentes de la Fuerza Pública y del Organismo de Investigación Judicial invadieron el campus de la ucr, provocando un enfrentamiento con estudiantes, docentes $y$ personal administrativo.

En 2011, la Dra. Yamileth González García, Rectora de la ucr, en el periodo 2004-2012, dispuso crear la Comisión Institucional de Autonomía Universitaria, con la finalidad de desarrollar diversas actividades que sirvieran para relevar el tema de la autonomía universitaria y para colocarlo en la discusión y la reflexión universitaria. Esta Comisión llevó a cabo varias acciones, dentro de las que destaca la realización de un taller con las direcciones de distintas unidades académicas, así como, la propuesta de incorporar el tema de la autonomía universitaria en los contenidos del curso de Didáctica Universitaria, el cual se imparte todos los años a la comunidad docente de la universidad.

La autonomía universitaria representa una cuestión compleja. Dentro de la propia comunidad universitaria no deja de manifestarse la existencia de percepciones $y$ aprehensiones diferentes acerca de ella, algunas bien informadas y otras quizá no tanto. Esta es una situación que en general, puede decirse que es bastante lógica. En parte, lo es porque las percepciones varían según cada sector de la comunidad universitaria e incluso, según las diferentes unidades académicas. Pero lo es también, porque pareciera que la autonomía había pasado ya a ser un tema de poca o ninguna preocupación en la Universidad.

En el presente artículo se tiene por finalidades: a) realizar una aproximación al concepto de la autonomía universitaria, con base en la acepción que adquirió en América Latina, a partir del Movimiento de Córdoba; b) hacer una breve reseña acerca del significado que toma ese concepto en Costa Rica, a propósito de la creación de la Universidad de Costa Rica, en 1940 y c) indicar la necesidad de plantearse el análisis y la reflexión, en torno a las implicaciones que acarrea para la autonomía universitaria y para el quehacer de la universidad pública, el desarrollo de las políticas públicas que en Costa Rica, durante el último cuarto de siglo, han propugnado por una transformación institucional del Estado, la cual se rige por la privatización y por la instauración de un esquema de desarrollo basado en la apertura comercial, la inversión extranjera directa y los tratados internacionales de libre comercio.

\section{CONCEPTO DE AUTONOMÍA UNIVERSITARIA EN AMÉRICA LATINA}

En América Latina, la autonomía universitaria tiene su referencia común en la Reforma Universitaria de Córdoba de 1918. La acepción que se le adjudicó a la autonomía en aquel momento hizo especial énfasis en las siguientes cuestiones principales:

... el reconocimiento del derecho de la comunidad universitaria a elegir sus propias autoridades, sin interferencias extrañas; la libertad de cátedra; la designación de los profesores mediante procedimientos puramente académicos que garantizaran su idoneidad; la dirección y gobierno de la institución por sus propios órganos directivos; la aprobación de planes y programas de estudio; elaboración $y$ aprobación del presupuesto universitario, etcétera (Tünnermann, 2006: 22).

A partir de las reformas de Córdoba, la autonomía universitaria se convirtió en una condición de referencia esencial para las universidades de América Latina, lo mismo que en una atribución institucional que en varios de los países llegó a quedar consignada en las cartas constitucionales, asignándosele una jerarquía jurídica especial.

La concepción de universidad y de la autonomía universitaria adoptada en América Latina a partir de Córdoba, además de enunciar y estipular una esencial independencia respecto a los distintos poderes del Estado y del gobierno, se basa también en una concepción laica y humanística del saber y de 
las actividades académicas. La nueva universidad latinoamericana proclama una múltiple apertura hacia la sociedad, en procura de llegar con los beneficios de su quehacer académico, al conjunto de las comunidades nacionales en general.

Según A. Didriksson, a diferencia de la acepción que adquirió en otras regiones del mundo - relacionada de manera especial con la libertad académica - en América Latina, la autonomía universitaria alcanzó a asumir implicaciones aún más profundas y quedó enmarcada en estrecha asociación con la naturaleza pública y de bien social de la educación superior. El significado de la autonomía en la universidad latinoamericana quedó así referido a "la construcción de un nuevo mundo, a la intelectualidad de muchos países, a la idea de un proyecto cultural nacional y a la lógica más imperecedera de una siempre anunciada y más bien deseada integración latinoamericana y caribeña" (Didriksson, 2006: 3).

Esa acepción de la autonomía universitaria indica que: a) la universidad es en la sociedad una institución emancipadora, liberadora, cuya actividad se orienta de manera privilegiada a contribuir con la construcción de la institucionalidad democrática de la nación $y$ b) su matriz de referencia es la libertad de pensamiento $y$ de expresión, entendiendo que el conocimiento debe ser generado en todos los campos, sin restricciones de ninguna índole. La autonomía del conocimiento, lo mismo que su carácter de bien público social, son condiciones que deben prevalecer en la universidad. El conocimiento no solo libera de la ignorancia y la pobreza, el despotismo, la injusticia social, la inequidad, la rigidez opresiva de las estructuras del poder, sino que además humaniza a la sociedad $y$ da sustento a los más nobles ideales de la convivencia en democracia. Por eso mismo, en América Latina, la universidad pública es concebida como una institución de cultura superior; la más eminente institución de la libertad en la sociedad.

Lo anterior implica que la universidad debe desarrollar su quehacer académico en todos los ámbitos del conocimiento, sin la interferencia de las directrices que se le pudiera querer imponer por parte de las autoridades de gobierno o por parte de cualquiera otra institución o entidad externa. En eso reside la esencial importancia de la autonomía universitaria.

En una formulación adoptada en 1966, por el Consejo Universitario de la Universidad Nacional Autónoma de México (unam), se plantea lo siguiente:

Autonomía universitaria es esencialmente la libertad de enseñar, investigar y difundir la cultura. Esta autonomía académica no existe de un modo completo si la universidad no tuviera el derecho de organizarse, de funcionar $y$ de aplicar sus recursos económicos como lo estime más conveniente, es decir, si no poseyera una autonomía administrativa; y si no disfrutara de una autonomía legislativa, que es su capacidad para dictarse sus propios ordenamientos (Ornelas, 2008: 32).

En la anterior formulación se proponen tres dimensiones distintas de la autonomía universitaria: académica, administrativa y legislativa. Sin embargo, dentro de las tres se destaca la de la autonomía académica. De ella se entiende que vendrían a ser tributarias las otras dos dimensiones. Una diferenciación similar en contexto argentino, es también indicada por Mollis. Esta investigadora distingue las dimensiones académica, financiera y administrativa (2008: 94).

La consideración de las disposiciones constitucionales que dan su sustento institucional a la autonomía universitaria constituye una base principal, a partir de la cual ha de plantearse cualquier análisis, reflexión y discusión, en torno al ejercicio de la autonomía en la universidad. Esa viene a ser la dimensión administrativa; no obstante, la autonomía tampoco puede quedar restringida a hacerse efectiva en el marco de las relaciones instrumentales y operativas que la universidad desarrolla y que mantiene con el Estado, las autoridades de gobierno y otros actores de la sociedad.

La autonomía universitaria es matriz fundante de identidad cultural, histórica, académica e institucional para la universidad, antes que una codificación técnica e 
instrumental de normatividad regulada jurídicamente. Entre una y otra de estas dos dimensiones de referencia, no se trata de establecer yuxtaposiciones, lo que cabe destacar, antes bien, es que en todo caso, entre ambas dimensiones debe existir siempre una relación dinámica, a fin de que la autonomía pueda realizarse de manera permanente como un principio activo que da sustentación al quehacer académico de la universidad:

... la cuestión de la autonomía universitaria adquiere una doble connotación: por un lado, se trata de afirmar la capacidad jurídica (...) en los hechos sin que la dependencia de recursos respecto del estado limite tal actividad o las amenazas del juego político condicionen la libertad del gobierno interno; a su vez, se trata de afirmar la legitimidad de la universidad como ente rector en la producción de la cultura, la profesionalidad y la ciencia, de manera tal que, en un momento histórico dado, se le reconoce al conjunto de universidades autónomas la plena capacidad de decidir e influir en el desarrollo de las profesiones, la enseñanza superior y el conocimiento científico. Es decir, poder político para su propio manejo y poder político (sin injerencia estatal directa) en el desarrollo de la sociedad en los aspectos que le conciernen (Vaccarezza, 2006: 36).

No existe ninguna otra forma de que la universidad pueda dar sustentación al valor absoluto de la autonomía, si no es a través de su relación de diálogo e interlocución con las distintas instancias actorales de la sociedad: "la autonomía (...) no es ni puede ser mera concesión formal de una clase, ni su ejercicio una libertad académica en abstracto, al margen de fuerzas, procesos y situaciones históricas concretas" (Didriksson, 2006: 4).

... la universidad no es una institución autónoma que produce ideas que luego la sociedad consume o no. Todo lo contrario, se rige por complejos procesos de interacciones entre el estatuto de la ciencia, las profesiones y las disciplinas, la expansión o contracción del mercado de trabajo, las diferencias entre clases sociales, las minorías étnicas, el poder, los géneros, o la respectiva ubicación del trabajo manual e intelectual en la escala de valores sociales. En este sentido, la universidad se construye como una instancia de producción, control y legitimación en un contexto de tensión constante entre lo que la sociedad, el Estado $y$ el mercado productivo le delegan $y$ sus tradicionales funciones de producción y difusión del saber (Mollis, 2006: 88).

En la autonomía universitaria, la libertad de pensamiento $y$ de expresión tiene su más privilegiada matriz. En la medida que la universidad es una institución abierta y en interacción constante con la sociedad, la autonomía es esencial para garantizar que ella, en efecto, pueda contribuir con sus actividades a la construcción de la institucionalidad de una sociedad democrática.

La dimensión académica es fundamental. La autonomía administrativa puede ser fácilmente instrumentalizada. De hecho, esa es la dimensión instrumental de la autonomía. El rector o rectora de la universidad puede hacer uso instrumental de la autonomía para suscribir, por ejemplo, convenios con las empresas y otras entidades que vienen a facilitar recursos financieros a la institución, pero que traen también agendas acotadas de investigación o de formación profesional. Esta clase de acciones pueden llegar a ser de alto interés estratégico para las empresas, aunque no así para la universidad pública.

\section{AUTONOMÍA UNIVERSITARIA EN LA CREACIÓN DE LA UNIVERSIDAD DE COSTA RICA}

La autonomía universitaria refiere a una noción y a la constitución de una entidad que tiene su anclaje en territorialidades históricas, societales, culturales e institucionales específicas (Cunha, 2006: 13). Aun cuando, en un caso como el de las universidades públicas de América Latina, la autonomía universitaria haya tenido un origen común en las reformas 
acontecidas en el marco del Movimiento de Córdoba de 1918, es posible apreciar diferencias concretas de recepción y enfoque, lo mismo que de formulación jurídica y constitucional. En América Latina, en general, las condiciones específicas en las que la autonomía universitaria se despliega y cumple, dependen de los regímenes políticos de cada país y del lugar institucional que la universidad asume y ocupa en ellos (Vaccarezza, 2006: 33).

En Costa Rica, la autonomía universitaria ocupó un lugar central en la discusión desarrollada en la década de 1930, con motivo de la propuesta para crear la Universidad de Costa Rica (UCR). En el marco de esa discusión, a propósito de las características institucionales que había tenido en su desempeño y funciones, la primera universidad fundada en el país, la Universidad de Santo Tomás -abierta en 1843 y cerrada en 1888- L. Galdames recalcaba en indicar la condición de dependencia que siempre había existido en la relación establecida por dicha institución con respecto a las autoridades de gobierno. Además, a esa relación de dependencia se agregaba la injerencia que también habían llegado a tener los colegios profesionales sobre esa institución (Galdames, 1935: 47).

A inicios de la década de 1940, en el momento de creación de la UCR, el entonces Secretario de Educación del Gobierno de Costa Rica, Luis Demetrio Tinoco (citado por González), subrayaba lo siguiente:

La Universidad que nos proponemos establecer debe ser una Universidad nueva, una Universidad que responda a este octavo quinquenio del siglo $\mathrm{xx}$ en que vivimos. Debe ser una Universidad autónoma. Facultada para administrar sus bienes y rentas, para decretar sus reglamentos y estatutos, para establecer sus enseñanzas y organizar sus pruebas de examen. Debe ser también una Universidad donde los alumnos tengan representación en sus órganos de decisión (González, 2005: 30).

Según la anterior declaración, la autonomía universitaria quedaba entendida en Costa Rica como la más básica y esencial condición institucional con que debía contar la universidad. La autonomía era concebida como la matriz de referencia, a partir de la cual debían estar sustentadas todas las distintas dimensiones del quehacer académico y de la gestión institucional que le son inherentes a la universidad: organización y gobierno, administración de patrimonio y recursos, elección del proyecto pedagógico, oferta de formación, estructura académica y servicios que brinda a la sociedad.

Una cuestión esencial que forma parte de la concepción original de la autonomía universitaria en Costa Rica, es la de que la universidad, en tanto, no se puede entender sino como una institución inscrita en un proyecto de sociedad $y$ de nación, cuyas regulaciones normativas y constitucionales se fundamentan en los principios que han de regir la construcción de institucionalidades basadas en la libertad y en la organización democrática de la sociedad.

Esta aprehensión de la idea de universidad pública procede de la declaración formulada en el contexto de la Reforma Universitaria de Córdoba, según la cual, la universidad es una institución cuyo quehacer debe estar estrechamente vinculado a atender y contribuir con la solución de los problemas cruciales que afectan a la sociedad. La universidad es una institución que tiene una insoslayable responsabilidad social (Landinelli, 2008: 104), cuyo proyecto académico no puede ser definido de manera apropiada, en la medida que se mantenga restringido a la sola consideración de las propias actividades internas (Mariátegui, 2008: 205).

A la universidad pública se le asigna la función y la responsabilidad de aportar conocimientos, educación y cultura en toda su más diversa amplitud, a la vez que en el marco de una constante $y$ permanente relación de intercambio, interlocución y diálogo con la sociedad.

Por la especial naturaleza del quehacer académico que en ella se desarrolla, la universidad es entendida como la institución que ha de contribuir para clarificar las situaciones con las que la sociedad se compromete, para aportar en la construcción crítica y reflexiva de los mejores juicios de valor que definirán cuáles de dichas situaciones son las más adecuadas y en su lugar, cuáles en cambio ponen en riesgo 
la sustentabilidad de la institucionalidad democrática de la Nación. Para cumplir con tales funciones y responsabilidades, la autonomía universitaria es de una importancia fundamental.

A tal efecto, en Costa Rica, a mediados de la década de 1930, el entonces presidente R. Jiménez Oreamuno hacía énfasis en que la nueva universidad que estaba por crearse, debía quedar "enteramente a cubierto de cualquiera intromisión política, confesional o sectaria. Destinada al mantenimiento de la alta cultura $y$ la difusión del saber... por encima de las pasiones que enconan y dividen a los hombres" (Galdames, 1935: 82).

... la universidad no debe estar bajo ninguna sombra, sino a la luz meridiana; el gobierno, regente de la universidad, le da sombra, como se la daría cualquiera secta filosófica, científica o religiosa; la universidad debe ser absolutamente libre, sin bandera, sin tendencia, sin secta (Galdames, 1935: 80-81).

Según subraya Monge: "para nuestros gobernantes la autonomía era la esencia y como lo he dicho muchas veces, la naturaleza fundamental del ser universitario. La autonomía viene a ser un giro ontológico de la Universidad" (1994: 3). La autonomía universitaria quedaba entendida como íntimamente asociada "a la concepción de vida y al régimen democrático de un país" (1994: 2). Así, a la universidad se le confía la especial tarea y responsabilidad de ser en una sociedad democrática, la institución de "síntesis y de orientación crítica" (Freitag, 2004: 30); es decir, tal como se consigna en el artículo 84 de la Constitución Política de Costa Rica, una institución de "cultura superior".

La noción de cultura superior se vincula con la búsqueda inagotable de la Verdad, el Bien, la Belleza, la Justicia, con el cultivo elevado de la inteligencia, de la ciencia, del arte, de la técnica; con todo aquello que tenga relación con la condición humana y su perfeccionamiento, con el proceso de humanización en todos sus ámbitos (Baudrit, 2009: 4).
A propósito de la creación de la Universidad de Costa Rica, según señala Galdames, se le otorgó en aquel momento a la autonomía universitaria $y$ a la cultura superior "la prerrogativa que desde tanto tiempo reclama. Jurídicamente, la institución universitaria se erige en un poder público, en el poder espiritual de la nación" (1935: 83).

Según este autor, esta concepción de la universidad pública y de la autonomía universitaria, no había sido todavía vista como viable hasta ese momento en ningún otro país de América Latina. En tal sentido, con la acepción que en la década de 1930, se le dio a la autonomía universitaria en Costa Rica, se llegó a alcanzar "por primera vez en América el ideal máximo de la soberanía de una corporación docta perteneciente al Estado" (Galdames, 1935: 82).

El modelo de universidad pública instituido en Costa Rica a partir de la creación de la ucr, según cabe apreciar, está íntimamente ligado a los enunciados fundamentales de la Reforma de Córdoba: autogobierno y elección por parte de la comunidad universitaria de las autoridades de la institución, participación de la comunidad estudiantil en el gobierno universitario, definición propia de los planes de estudio $y$ de la oferta académica, libertad de cátedra, vinculación de la universidad con la sociedad para la difusión del conocimiento y la cultura, independencia de las autoridades de gobierno y autonomía universitaria (Landinelli, 2008: 105).

En la universidad queda depositada la responsabilidad de orientar a la sociedad en la construcción y fortalecimiento de una cultura nacional basada en el humanismo y en las instituciones de la democracia, como requisito insoslayable para el logro del bienestar común de la colectividad nacional. La universidad, lugar natural del pensamiento libre $y$ de la libertad de expresión, ha de ser una institución cuyo quehacer académico debe orientarse en razón de contribuir con el desarrollo de las más nobles tareas civilizatorias, a las cuales puede aspirar un pueblo y una nación.

\section{CUESTIONES DEL PRESENTE}

Tanto en la dimensión de sus relaciones externas como en la de su propia organización 
interna, la universidad no puede ser entendida sino como una institución que se encuentra siempre en proceso de desarrollo y cambio. A la universidad le es consustancial lo que cabría denominar como el ejercicio permanente de un "principio de institucionalización". Por las actividades que lleva a cabo y el protagonismo que ella tiene en la sociedad, la universidad se encuentra inscrita siempre en un contexto de procesos instituyentes.

La universidad mantiene múltiples $y$ complejas relaciones con diversas instancias y actores de la sociedad. A tal efecto, la definición de su proyecto académico tiene como marco de referencia, no solo los intereses en general de la sociedad, sino también los intereses específicos de diversas entidades externas a ella, públicas y privadas. El ejercicio activo de la autonomía universitaria dota a la universidad de las condiciones para que sea ella misma la que con fundamento en su propia responsabilidad de conocer cuáles son las realidades del país y cuáles las necesidades de la sociedad, pueda de manera apropiada organizar su proyecto académico y las funciones sustantivas que le son propias, bajo una perspectiva de presente y futuro, atendiendo las necesidades tanto de la coyuntura como las de largo plazo.

Naturalmente, la universidad está también llamada a aprovechar sus actividades para llevar a cabo en la sociedad una labor educativa $y$ cultural a profundidad. Sus capacidades de análisis, de reflexión y de crítica deben ser distribuidas y puestas al servicio de los diferentes sectores de la sociedad. Es importante recordar al respecto la referencia fundamental en la que se enfoca la Reforma Universitaria de Córdoba: la universidad pública es una institución que debe contribuir con el desarrollo de las transformaciones sociales que conduzcan a la sociedad democrática.

Al respecto, cabe recordar aquí lo que se estipula en el artículo tercero del Estatuto Orgánico de la Universidad de Costa Rica:

La Universidad de Costa Rica debe contribuir con las transformaciones que la sociedad necesita para el logro del bien común, mediante una política dirigida a la consecución de una justicia social, de equidad, del desarrollo integral, de la libertad plena $y$ de la total independencia de nuestro pueblo (Universidad de Costa Rica, 2014: 1).

Según lo anterior, la universidad está involucrada y comprometida por definición y de manera esencial con una actividad de análisis $y$ de reflexión crítica permanentes, respecto de las necesidades $y$ los problemas de la sociedad $y$ del país. Tal como lo señala González:

La Universidad, hoy más que nunca, sabe que no puede permanecer al margen del debate y que, como escucha de los distintos planteamientos sociales, forjadora de valores ciudadanos $y$ formadora de opinión, debe sugerir, inspirar y responder. (...) La Universidad tiene que hacer uso de su liderazgo, de su capacidad reflexiva, de sus conocimientos, de su capacidad de diálogo, de su pluralidad como una fuerza para resolver problemas o al menos orientarlos hacia la consecución de objetivos sociales (2005: 10).

La naturaleza institucional y académica de la universidad pública está definida por la condición básica de ser una institución de cultura superior, en la que se cultivan, difunden $y$ protegen "las ciencias, las letras y las artes" (Galdames, 1935: 30). La actividad académica de la universidad, en todas las dimensiones en que se lleva a cabo, es patrimonio universal de toda la sociedad.

La universidad tiene como características que la definen, la libertad de pensamiento $y$ de expresión, el intercambio de las ideas, el respeto por la pluralidad, la diversidad y la alteridad. Es en esto en lo que consiste su ser así, en tanto que universidad: universitas. La universidad expresa y representa la universalidad, entendida esta como la diversidad, la pluralidad y la alteridad de la condición humana y de la sociedad, en general.

En el presente, para la universidad pública ha venido a quedar abierto un nuevo marco de condiciones. En particular, eso tiene que ver con las transformaciones institucionales del 
Estado costarricense, que han sido impulsadas a propósito de la instauración de un nuevo modelo económico, basado en la apertura comercial, la inversión extranjera directa y los tratados internacionales de libre comercio. Se trata de una institucionalidad tecnocrática, autoritaria, dedicada a la administración de lo que aún queda del Estado Social de Derecho y que poco a poco se va instituyendo y consolidando. Emergen los principios de la eficiencia, la eficacia y la competitividad, en un contexto de procesos de privatización y mercantilización de los servicios públicos.

En el caso de la universidad pública, en el marco de esos procesos se le establecen mecanismos que buscan intervenir en ella desde afuera, para recortar, direccionar, ordenar y controlar la orientación y el desarrollo de su quehacer académico y de las actividades de la gestión. Indicadores y estándares de eficiencia, eficacia, rendimiento econométrico y competitividad, pasan a interponérsele a la universidad, bajo la forma, por ejemplo, de protocolos $y$ modelos estandarizados de evaluación y acreditación, medición de la productividad científica (publicaciones), triangulación de la investigación con la empresa y el Estado, rendición de cuentas ajustada a las pautas de la gerencia empresarial, etc.

El saber se mide con el lenguaje de las finanzas; se calcula por medio de indicadores de rendimiento, a través de certificados y diplomas entregados en tiempo $y$ forma con mayor valor de mercado; se representa en la formación de recursos humanos cuando, al mismo tiempo, las humanidades van perdiendo gradualmente sus recursos. Nuestras universidades tienen alterada su identidad como instituciones de los saberes, $y$ van hacia la construcción de una nueva identidad que las asemeja al "supermercado", donde el estudiante es consumidor, los saberes una mercancía y el profesor un asalariado enseñante (Mollis, 2006: 87).

Un nuevo lenguaje aparece acerca de la universidad, para dar sustento a esas nuevas condiciones que se le buscan establecer. En varias ocasiones, ese nuevo lenguaje penetra $y$ se incorpora incluso, en el propio discurso académico. En manos de la experticia académica se deja el encargo de elaborar los instrumentos que habrán de venir a premiar o castigar a la universidad. En la medida que eso sucede, la universidad pública se desvirtúa a sí misma y ya no se reconoce como tal, o encuentra diversas dificultades para hacerlo.

A la universidad pública se le interpone el imaginario de que no podrá estar a la altura de las exigencias del presente, en la medida que no sea capaz de desarrollar las capacidades de competitividad que la saquen de la invisibilidad y del estrecho espacio de su localización nacional. La privatización, la diferenciación institucional, la segmentación de los sistemas de educación superior, la oferta transfronteriza de titulaciones, todas estas constituyen las condiciones en las que ahora la universidad pública está inscrita y que la inducen a adoptar las lógicas de la competitividad. Se le señala que esta debe asumir también como estrategia, el desarrollo de nichos de especialización académica y de producción científica, que le permitan ganar colocaciones en la escala de los rankings mundiales de universidades. Cuando la universidad pasa a tomar en cuenta tal tipo de demandas, ellas se asumen e incorporan en la política académica institucional como si se tratara de decisiones propias.

La idea de universidad pública latinoamericana durante el siglo xx (ya fuera de gestión pública o privada, como son las universidades de las iglesias) connotaba calidad científica, relevancia social, pertinencia y equidad. Se diferencia de la idea de universidad corporativa del siglo xxI, que significa fin de lucro, intereses privados, exclusión social y predominio de las ambiciones de los propietarios (Mollis, 2006: 98).

En un contexto nacional como el mencionado, donde se constituye un aparato de Estado cuya nueva racionalidad institucional tiende a profundizar la desigualdad social, económica, política y cultural en la sociedad, además de hacerlo a contrapelo y en detrimento 
de las vías de la democracia, la universidad pública queda colocada en una situación de encrucijada. Por una parte, ella puede tomar la decisión de adecuarse al nuevo modelo de universidad que la institucionalidad emergente del Estado le demanda adoptar, incorporando procesos internos de privatización y mercantilización, desnaturalizando y distorsionando el principio de la responsabilidad social que la define, convirtiendo la pertinencia de su quehacer académico en una cuestión de gerencia empresarial, referida a la vinculación externa con el mercado y enfocada en el desarrollo de las capacidades para la competitividad. Por la otra, la universidad puede en cambio impulsar procesos de transformación que le permitan recuperar, validar $y$ dar nuevas perspectivas a su proyecto académico, finalidades y funciones, en procura de revalidarse como universidad pública y como institución de cultura superior que responde a la responsabilidad de ser en la sociedad una institución activa y protagónica, con un compromiso claro en la defensa de la institucionalidad de la democracia y por la búsqueda del bien común.

La perspectiva de la sociedad democrática y del papel protagónico que la universidad pública asume que debe jugar en el marco del sistema institucional del país, es algo que en el mejor de los casos, ella no puede hacer valer sino en el contexto de una compleja red de tensiones. Además, a falta de una sociedad en la que los diferentes sectores sociales subordinados que la integran tengan la capacidad $y$ la disposición para hacer valer sus específicos intereses en relación con los servicios que la universidad desarrolla, es que la propia universidad debe hacer valer sus convicciones democráticas, con una firme voluntad ética y con un genuino sentido de su responsabilidad social.

El académico brasileño Pablo Gentili se vuelve contra quienes hoy, en América Latina, desde una posición conservadora y tecnocrática buscan impulsar en la universidad, reformas basadas en "políticas de privatización y mercantilización de la educación superior y no de aquellos que defienden una perspectiva transformadora $y$ emancipadora para nuestras sociedades y sus universidades" (2008: 39).
Las universidades deben ser espacios de producción y difusión de los conocimientos socialmente necesarios para comprender $y$ transformar el mundo en que vivimos, entenderlo de formas diversas y abiertas, siendo el campo donde el debate acerca de esta comprensión se torna inevitable y necesario. Las universidades nos ayudan a leer el mundo, a entenderlo y a imaginarlo (Gentili, 2008: 48).

¿Puede hoy la universidad pública decidir por sí misma qué rumbo tomar? ¿Puede ella decidir en realidad cuál es el modelo de universidad que le va a presentar $y$ ofrecer a la sociedad? Estas cuestiones, en todo caso, debieran ser planteadas, analizadas y discutidas con claridad, transparencia, prolijidad $y$ de manera abierta en la universidad. No obstante, hasta ahora da la impresión de que lo predominante es más bien la indiferencia en la comunidad universitaria, además de que en la institución se observa también cierta limitación interna para el abordaje y discusión de ese tipo de cuestiones, debido quizá a que en la universidad también existen ciertas limitaciones para el ejercicio de una genuina deliberación democrática (Vaccarezza, 2006: 37). No es rara la ocasión en que la autoridad universitaria adopta una posición de administración gerencial, autoritaria, excluyente, clientelar, antes que la de una apropiada gestión académica universitaria: inclusiva, dialógica, respetuosa; en último término, democrática. Hoy ya no es suficiente con la declaración, según la cual la universidad pública:

... es el mundo privilegiado de la academia, de las ciencias y tecnologías, del saber, de la cultura y de las artes, $y$ que como tal debe ser la esfera por antonomasia de la libertad de pensamiento $y$ de expresión y el reino máximo de la tolerancia $y$ del reconocimiento del pluralismo... En esa perspectiva, hay que decir, una y otra vez, que la Universidad está comprometida por los cambios que se vienen escenificando en esta época histórica del capitalismo que estamos viviendo. No se trata, como en otros momentos, de transformaciones de coyuntura, 
sino de una reorganización profunda de la organización social productiva que ha hecho obsoletos los mismos paradigmas explicativos o críticos que quizás fueron válidos en otros momentos (Moncayo, 2008: 26).

Para Ornelas, la defensa de la autonomía universitaria hoy está especialmente definida por la lucha:

... contra la privatización, la desnacionalización y la usurpación de las instituciones públicas $y$ nacionales para convertirlas en empresas mercantiles... contra la transformación de la educación en mercancía y contra la lógica del neoliberalismo que desconoce la razón social y la sustituye por la razón económica, intentando convertir en sentido común la consideración de que la medida del éxito de toda empresa, como la de cualquier persona, es la máxima ganancia, el enriquecimiento o la distinción personal (2008: 33).

Según lo anterior, Ornelas, se sitúa también en la raíz académica de la autonomía universitaria, en la matriz civilizatoria y en la misión cultural de la universidad pública. Su planteamiento está inscrito en la preocupación por señalar cuál es la encrucijada en la que hoy a la universidad le corresponde desarrollar sus actividades, para cumplir con su más alta misión de ser una institución de cultura superior. Los términos de la encrucijada son los mismos que ya se mencionaron anteriormente: a) institucionalización de la privatización y la mercantilización y el desmantelamiento del Estado Social de Derecho y b) la defensa y reafirmación de la naturaleza institucional y la identidad académica de la universidad, fundadas en la libertad de pensamiento y de expresión, en una actividad académica crítica, reflexiva, dialógica $y$ que posee una clara referencialidad ética de compromiso con la sociedad y con las instituciones de la democracia.

La importancia de relevar la dimensión académica de la autonomía remite a la necesaria reflexión que debe prevalecer en la universidad, acerca del significado social de todo el quehacer académico que en ella se lleva a cabo. No es suficiente con hacer una aplicación instrumental de la autonomía, si en la universidad se están empezando a desarrollar prácticas y a adoptar orientaciones que vienen a desvirtuar, por ejemplo, la naturaleza del conocimiento como un bien público. O bien, en su lugar, cuando la autoridad universitaria toma decisiones que tienden a paralizar el ejercicio de la libertad de pensamiento y de expresión. De igual manera, cuando las políticas institucionales ajustan sus criterios sobre lo que se entiende por excelencia académica, para ponerlas en consonancia con los indicadores y estándares de calidad que imponen los organismos financieros internacionales u otro tipo de organización internacional. En situaciones como esas, la autonomía pierde solidez y se transforma en una mampara que sirve para validar precisamente aquello mismo que la está socavando: "la autonomía puede ser un peligroso eslogan si sólo idealiza la historia y esconde los intereses y visiones sobre la universidad, la educación y el país que se confrontan en torno a ella" (Aboites, 2008: 80).

\section{CONSIDERACIONES FINALES}

En Costa Rica, la discusión sobre la autonomía universitaria no parece haber despertado todavía mayor interés en las comunidades de la universidad pública. De vez en cuando se le nombra y se le da importancia, pero eso sucede casi siempre como resultado de ciertas situaciones especiales que se producen y que alcanzan a afectar la institucionalidad jurídica de la universidad. Así ocurrió, por ejemplo, en ocasión de la invasión de agentes de la Fuerza Pública y del Organismo de Investigación Judicial al campus de la ucr, en abril de 2010.

Según se ha indicado en este artículo, en Costa Rica la autonomía universitaria está asociada a una concepción de universidad pública, la cual tiene como su marco de referencia privilegiado, la construcción y fortalecimiento de la institucionalidad de la sociedad democrática. En tanto institución de cultura superior y por su trayectoria histórica, la universidad pública costarricense ha mantenido 
una orientación dirigida a contribuir con las transformaciones que la sociedad necesita para el logro del bien común.

Sin embargo, en la actualidad, el sistema de las instituciones públicas del país ha variado en sus formas de actuación como en el cumplimiento concreto de sus finalidades. El país ha entrado en un nuevo modelo de desarrollo $y$ de organización institucional de la sociedad, que se diferencia de manera significativa del modelo del Estado Social de Derecho (EsD), consagrado en la Constitución Política de 1949. En dicho marco, la universidad pública ha pasado a ser ahora, dentro de las instituciones del ESD, quizá la última de ellas que todavía ha logrado mantenerse en pie. En su lugar, cabe decir que esto ha sucedido así, en virtud y en buena medida debido a la especial condición institucional que la autonomía universitaria ha otorgado a estas instituciones.

Con todo, tal como también se ha indicado en este texto, la universidad pública en Costa Rica, lo mismo que la universidad latinoamericana en general, ha venido siendo objeto de tendencias de transformación y de cambios en la política pública sobre educación superior, que la han llevado a comprometerse con las nuevas dinámicas y reglas del juego emergentes e instituidas en el marco del sistema económico, del nuevo modelo de desarrollo y de la transformación del sistema institucional del EsD. Esos cambios tienden a repercutir de manera significativa en la autonomía universitaria. En particular, es posible advertir que tales cambios se dirigen a socavar la autonomía en su dimensión académica, para desproveerla de ella y en su lugar, relevar como única, legítima y viable, la dimensión instrumental que la define.

En este sentido, a la universidad se le cuestiona $y$ presiona para que haga un uso socialmente responsable de la autonomía, en razón, por ejemplo, de la ampliación y fortalecimiento de sus acciones de vinculación externa para la venta de servicios. Bajo una perspectiva como esa, se propone que la universidad haría un uso socialmente responsable de la autonomía, en la medida que se haga cargo de desarrollar estrategias y mecanismos para generar sus propios recursos y para que no dependa tanto de los presupuestos estatales.

En este sentido, se vuelve crucial para la comunidad universitaria una toma de conciencia reflexiva, informada, crítica, la cual no puede tener un anclaje apropiado si no es en la escena de las propias prácticas académicas cotidianas, en la cultura institucional, así como, en las modalidades y perspectivas de la gestión institucional. En la medida que esto suceda, la autonomía universitaria asume su legítima condición, lo mismo en su dimensión normativa o instrumental como en su dimensión académica, siendo esta última la más importante.

En la universidad, la autonomía representa un acontecimiento siempre presente $y$ de implicaciones institucionales irreducibles. Sin embargo, la autonomía también puede llegar a condensarse en la cristalización de inercias institucionales, en una axiomática formalizada pero carente de mayor significado. De esta manera, la autonomía universitaria puede llegar a ser desvirtuada a partir de la propia universidad.

Actualmente, la autonomía universitaria amerita ser colocada urgentemente en la agenda académica de la universidad pública. En ello está en juego la propia sobrevivencia de estas instituciones, en su condición de ser centros de cultura superior y como tales, tienen asumido un compromiso con una visión de sociedad $y$ de nación que se basa en la construcción y fortalecimiento de la institucionalidad de la democracia. En manos de las comunidades universitarias está la vigencia de la autonomía universitaria y de la propia universidad pública.

\section{BIBLIOGRAFÍA}

Aboites, Hugo. "La autonomía en México. Entre la libertad, el Estado y el interés privado". La reforma universitaria: desafíos y perspectivas noventa años después. Emir Sader, Pablo Gentili y Hugo Aboites (eds.). Buenos Aires. CLACso, 2008: 80-85. En: <http://bibliotecavirtual.clacso.org. ar/clacso/gt/20101109062939/sader.pdf> [consultado el 15 de julio de 2013].

Baudrit Carrillo, Luis. Autonomía universitaria y control de la Hacienda Pública. San 
Pedro de Montes de Oca, Costa Rica: SIEDIN/UCR, 2009.

Cunha, Luiz Antonio. "Autonomia universitá: teoría e prática". Universidad e investigación científica. Hebe Vessuri (comp.). Buenos Aires. Clacso, 2006: 13-31.

Didriksson, Axel. "La autonomía universitaria desde su contemporaneidad". Universidades 31. Ciudad de México. UDUAL, enero-junio 2006.

Freitag, Michel. El naufragio de la universidad $y$ otros ensayos de epistemología politica. Barcelona: Ediciones Pomares, 2004.

Galdames, Luis. La universidad autónoma. San José, Costa Rica: Editorial Borrasé, 1935.

Gentili, Pablo. “Una vergüenza menos, una libertad más'. La reforma universitaria en clave de futuro". La reforma universitaria: desafios y perspectivas noventa años después. Emir Sader, Pablo Gentili y Hugo Aboites (eds.). Buenos Aires. Clacso, 2008: 36-50. En: $<$ http://bibliotecavirtual.clacso.org.ar/ clacso/gt/20101109062939/sader.pdf> [consultado el 15 de julio de 2013].

González García, Yamileth. Informe de labores 2004/2005. San José, Costa Rica: Publicaciones de la Universidad de Costa Rica, 2005.

Landinelli, Jorge. "Trazos del Movimiento Reformista Universitario en Uruguay". La reforma universitaria: desafios y perspectivas noventa años después. Emir Sader, Pablo Gentili y Hugo Aboites (eds.). Buenos Aires. Clacso, 2008: 104111. En: <http://bibliotecavirtual.clacso. org.ar/clacso/gt/20101109062939/sader. pdf $>$ [consultado el 15 de julio de 2013].

Mariátegui, José Carlos. La reforma universitaria: desafios y perspectivas noventa años después. Emir Sader, Pablo Gentili y Hugo Aboites (eds.). Buenos Aires. Clacso, 2008: 204-212. En: <http://bibliotecavirtual.clacso. org.ar/clacso/gt/20101109062939/ sader.pdf $>$ [consultado el 15 de julio de 2013].

Mollis, Marcela. "Geopolítica del saber: biografías recientes de las universidades latinoamericanas". Universidad $e$ investigación científica. Hebe Vessuri (comp.). Buenos Aires. Clacso, 2006: 85-101.

Mollis, Marcela. "Las huellas de la reforma en la crisis universitaria argentina". La reforma universitaria: desafíos $y$ perspectivas noventa años después. Emir Sader, Pablo Gentili y Hugo Aboites (eds.). Buenos Aires. CLACSO, 2008: 86-103. En: <http:// bibliotecavirtual.clacso.org.ar/clacso/ gt/20101109062939/sader.pdf > [consultado el 15 de julio de 2013].

Moncayo, Víctor Manuel. "Permanencia, continuidad y cambio del movimiento universitario. (Reflexiones a propósito de la evocación de la Reforma de Córdoba)". La reforma universitaria: desafíos y perspectivas noventa años después. Emir Sader, Pablo Gentili y Hugo Aboites (eds.). Buenos Aires. Clacso, 2008: 20-29. En: <http:// bibliotecavirtual.clacso.org.ar/clacso/ gt/20101109062939/sader.pdf > [consultado el 15 de julio de 2013].

Monge Alfaro, Carlos. "La raíz costarricense de la autonomía universitaria". Reflexiones 24. San José, Universidad de Costa Rica. Julio 1994. En: <http://www.reflexiones. fcs.ucr.ac.cr/documentos/24/la_raiz.pdf .

Ornelas Delgado, Jaime. "Reflexiones en torno a la autonomía universitaria". La reforma universitaria: desafios $y$ perspectivas noventa años después. Emir Sader, Pablo Gentili y Hugo Aboites (eds.). Buenos Aires. Clacso, 2008: 30-35. <http:// bibliotecavirtual.clacso.org.ar/ clacso/gt/20101109062939/sader.pdf> [consultado el 15 de julio de 2013].

Tünnermann Bernheim, Carlos. "La autonomía universitaria frente al mundo 
globalizado". Universidades 31. Ciudad de México: Udual, enero-junio 2006.

Universidad de Costa Rica. Estatuto Orgánico. 2014. En: <http://www.cu.ucr.ac.cr/ normativ/estatuto_organico.pdf. .

Vaccarezza, Leonardo Silvio. "Autonomía universitaria, reformas y transformación social". Universidad e investigación científica. Hebe Vessuri (comp.). Buenos Aires. Clacso, 2006: 33-49.

Fecha de ingreso: 23/07/2013 Fecha de aprobación: 30/09/2013 
